\section{Though HIV is the main cause of AIDS, other factors play a role}

Sir - Although I entirely endorse the stand taken by the authors of the Durban Declaration $^{1}$, I think that HIV is the principal, rather than the sole, initiating factor of the current world pandemic of AIDS. I believe this for the following reasons.

First, from my experience of secondary or acquired immune deficiency in treated lymphoma patients who are HIV negative and in patients who have chronic graftversus-host disease after a transplant, HIV is not the only mechanism for adults developing the clinical syndrome. Second, external influences such as immune stimuli can modify progression, as demonstrated when haemophiliacs given recombinant factor VIII have a slower loss of CD4 lymphocytes than those who receive immunogenic serum protein containing factor VIII concentrates $^{2}$. Third, poor nutritional status identified on the basis of low vitamin A levels is associated with increased viral shedding ${ }^{3}$. This augments HIV perinatal transmission rate in breastfeeding African women ${ }^{4}$ and non-breastfeeding US women ${ }^{5}$. Fourth, general genital hygiene ${ }^{6}$, underage sexual activity and circumcision ${ }^{7}$ all affect the risk of acquiring HIV infection.

It is appalling that, as Dorritie states in Correspondence $^{8}$, there may be a right-wing political agenda behind the campaign claiming AIDS is not caused by HIV. Nevertheless, other social factors are involved in the African aspects of this epidemic, such as Johannesburg's high incidence of rape, the myth that raping a virgin can cure AIDS, and the high level of non-HIV sexually transmitted diseases in sub-Saharan Africa ${ }^{9}$.

As a consequence, there are benefits to be gained from President Mbeki's call for scientists to address the nature of AIDS and its links to HIV in an African setting. Such an investigation could well conclude that investments such as educating young men in the basics of sexual hygiene, providing nutritional supplements for pregnant women and treating mastitis ${ }^{10}$ might produce greater gains than spending money on antenatal treatment with antiretroviral drugs.

R. T. D. Oliver

Department of Medical Oncology, Saint

Bartholomew's Hospital, London EC1A 7BE, UK

1. Nature 406, 15-16 (2000).

2. Hoot, K. \& Canty, D. Haemophilia 4, 704-713 (1998).

3. Mostad, S. B. et al. Lancet 350, 922-927 (1997).

4. Semba, R. D. et al. Lancet 343, 1593-1597 (1994).

Greenberg, B. L. et al. AIDS 11, 325-333 (1997).

6. Beral, V. et al. Lancet 339, 632-635 (1992).

Halperin, D. T. \& Bailey, R. C. Lancet 354, 1813-1815 (1999).

Dorritie, D. Nature 406, 13 (2000).

. Gerbase, A. C. et al. Lancet 351, 2-4 (1998).

10. Semba, R. D. et al. J. Infect. Dis. 180, $93-98$ (1999).

\section{Responsible aquaculture can aid food problems}

Sir - If agriculture were to arise today, knowing what we do about its impacts on the natural environment, biodiversity and poverty, it would probably encounter the same mixed reception as aquaculture. R. L. Naylor et al. ${ }^{1}$ give an excellent overview of the serious challenges facing aquaculture. As they show, in some cases it actually reduces fish supplies for human consumption.

Naylor et al. list four main goals for the industry: more farming of fish at low trophic levels (low on the food chain); reduction of fish meal and fish oil inputs in feed; development of integrated farming systems; and promotion of environmentally sound practices.

After 23 years of aquaculture research in Asia, Africa and the Pacific, the International Centre for Living Aquatic Resources Management (ICLARM) strongly supports these goals and adds a fifth: access for poor consumers and small-scale producers. Leasing and community organization can allow even landless people to become fish farmers and conduct profitable microenterprises if aid is well-targeted.

Non-government agencies are carrying out many such projects in countries such as Bangladesh, where fish can be up to $80 \%$ of animal protein consumed. They farm various species of carp (most importantly Catla catla, Labeo rohita and Cirrhinus mrigal), catfish (Clariusspp.)and tilapia (Oreochromis niloticus), which require low input levels. In the Pacific, we are showing the potential for farming giant clams (Tridacna spp.), blacklip pearl oysters (Pinctada margaritifera), hard and soft corals and tropical marine aquarium fish, and for restocking and enhancing the sea cucumber Holothuria scabra.

Small island developing states rely on marine resources for their income. French Polynesia and the Cook Islands, for example, use environmentally friendly aquaculture to rear blacklip pearl oysters, which are low on the food chain and — producing prized black pearls — are second only to tourism for bringing in foreign exchange. The value of the black pearl harvest in French Polynesia in 1999 was US\$200 million. Demand for cultured giant clams, and hard and soft corals, is increasing, and these can be grown on coral reefs with apparently no adverse impact. All these species and systems have been selected either for accessibility to poorer people, for environmental sustainability, or to supply products that are used locally.

Rising prices mean that fish must be cheap to produce, such as carp and tilapia, or poorer consumers will not benefit. M. Dey et al. ${ }^{2}$ show that adopting the improved strain of Nile tilapia will reduce tilapia price by $5-16 \%$ in Bangladesh, China, the Philippines, Thailand and Viet- nam. Poorer consumers will benefit most in all these countries except the Philippines.

Aquaculture can also restock high-value coral-reef species that have been severely depleted by over-fishing. In the small islands of the Pacific, research has paved the way for inshore marine resources to provide substantial income for coastal communities. Methods have been developed for culturing sea cucumbers, giant clams, trochus and green snail, and the emphasis of research is now on how best to release juveniles into the wild.

Release of cultured juveniles can also overcome the widespread problem of too few young fish returning to settle in the fishery area. Such practices have been used for 90 species in Japan over the past 30 years, particularly successfully in the case of the scallop.

Aquaculture and stock enhancement are still in their infancy, and some mistakes have been made in their development. New directions should follow the guidance outlined by Naylor et al.; they should also heed the questions of access by poorer societies and proceed wisely with stock enhancement under suitably safeguarded conditions. M. J. Williams, J. D. Bell, M. V. Gupta, M. Dey, M. Ahmed, M. Prein, S. Child, P. R. Gardiner, R. Brummett, D. Jamu ICLARM, World Fish Centre, PO Box 500 GPO, 10670 Penang, Malaysia

1. Naylor, R. L. et al. Nature 405, 1017-1024 (2000). 2. Dey, M. M. et al. Aquacult. Econ. Mgmt (in the press).

\section{Will we ever know what the Chinese knew?}

Sir — I was intrigued by recent letters about the Chinese medical treatise Su Wên and its apparent account of blood circulation. Prioreschi's argument (Nature 405,$993 ; 2000$ ), based on uncertainty about the exact meaning of certain words, is insufficient to disqualify the ancient Chinese as the discoverers of blood circulation. One's conclusion can be biased by the choice of translator as well as the translator's choice of words: an inevitable problem since this argument relies on excerpts of translated materials.

In order to make a fair judgement, one would have to consult the ancient Chinese text directly and treat the technical terms in accordance with standard definitions, as one would do with any other technical literature.

Until ancient Chinese knowledge of blood circulation is proved or disproved in an appropriate manner, it is safe just to say that Harvey made the suggestion that elicited the documented scientific experiments proving how the blood circulates. Ichikawa Shinji

FKAMPO(Traditional Japanese Medicine journal) 540-29 Ikeno, Ikeda-cho, Ibi-gun, 503-2424 Gifu, Japan 